\title{
Behavioural and physiological responses to pharmaceutical exposure in macroalgae and grazers from a Baltic Sea littoral community
}

\author{
Ann-Kristin Eriksson Wiklund ${ }^{1, *}$, Hanna Oskarsson ${ }^{2}$, Gunnar Thorsén ${ }^{3}$, \\ Linda Kumblad ${ }^{2}$
}

${ }^{1}$ Department of Applied Environmental Science, ${ }^{2}$ Department of Systems Ecology and ${ }^{3}$ Department of Analytical Chemistry, Stockholm University, 10691 Stockholm, Sweden

\begin{abstract}
Gammarus spp. and Fucus vesiculosus from the Baltic Sea littoral community were exposed to 3 concentrations of the pharmaceuticals ibuprofen and propranolol. Both physiological and behavioural parameters were measured to examine potential effects in the organisms. For Gammarus spp., respiration, feeding rate and activity with and without predator cues were measured, and gross production to respiration ratio (GP/R) and chlorophyll fluorescence were measured for $F$. vesiculosus. The results showed that propranolol decreased the activity related to movement, and Gammarus spp. could not compensate for the reduced movement when subjected to predator cues. The feeding rates of Gammarus spp. exposed to propranolol were more than 2 times higher at all concentrations compared to the control. Ibuprofen did not significantly affect any of the measured parameters of Gammarus spp. The GP/R was lower in algae exposed to propranolol. The effects of propranolol on both behaviour and physiology of Gammarus spp., in combination with the stress responses in the algae, might cause unexpected indirect and cascade effects which eventually could have implications at both community and ecosystem scales.
\end{abstract}

KEY WORDS: Propranolol - Ibuprofen - Gammarus spp. · Fucus vesiculosus - Behaviour · Feeding rate $\cdot$ Respiration $\cdot$ Production

Resale or republication not permitted without written consent of the publisher

\section{INTRODUCTION}

The semi-enclosed Baltic Sea is an interesting and important environment for ecotoxicological studies, as the area already struggles with abiotic stressors. The Baltic Sea is a brackish-water sea, with a salinity gradient ranging from only 2 psu in the north to $10 \mathrm{psu}$ in the south of the Baltic Proper (Kautsky \& Kautsky 2000). The brackish water causes osmotic stress in organisms of both marine and freshwater origin. For example, the amphipod Gammarus oceanicus is well adapted to a salinity of 7 psu (Normant \& Lamprecht 2006), but a slightly lower salinity of 5 to 7 psu is critical for survival and reproduction (Khlebovich 1990).
Gammarus spp. are widespread over several coastal aquatic biotopes, ranging from the sea to brackish-water and freshwater systems (Normant \& Lamprecht 2006). In the Baltic Sea, Gammarus spp. occur in high abundances among stands of the perennial macroalga Fucus vesiculosus (Kautsky et al. 1992). Mesoherbivores like Gammarus spp. and macroalgae like $F$. vesiculosus are interdependent and constitute an important key community of the Baltic Sea (Råberg \& Kautsky 2007). By feeding on the macroalgae, the amphipods both degrade the macroalgae itself and remove impeding epibiota (Orav-Kotta et al. 2009). Consequently, the amphipods affect the macroalgal structure and productivity 
(Arrontes 1999) and constitute an important link in the littoral community, connecting primary producers to secondary consumers in the coastal zone (MacNeil et al. 1999). These interactions are often chemically mediated. For example, Gammarus spp. use chemical cues both to localise food and to detect predators (De Lange et al. 2005, 2006). Amphipods respond differently to food searching and habitat selection depending on whether chemical cues from a predator are present (Zamzow et al. 2010).

The freshwater species Gammarus pulex has been frequently used in toxicity testing of metals, insecticides and pharmaceuticals and their influence on e.g. feeding activity (Taylor et al. 1993), scope for growth (Maltby et al. 1990), precopula separation (Pascoe et al. 1994) and behavioural responses (Gerhardt et al. 1994, 1998, 2003, Gerhardt 1995, 1996, De Lange et al. 2006). Behaviour is a sensitive endpoint of an animal's physiological response, with effects on both the individual and community level (Clotfelter et al. 2004). It has also been suggested that behavioural responses can occur at different stress levels (De Lange et al. 2009). At lower levels of disturbance, the behavioural response works as a stress indicator, which is a reversible effect. After prolonged exposure or at higher contaminant concentrations, the behavioural response can be an irreversible effect that can be used as a mortality indicator. In a stepwise stress model, many species showed a cascade of responses when exposed to higher contaminant concentrations or longer exposure (Gerhardt 1999, Gerhardt et al. 2005).

The release of human pharmaceuticals and their metabolites into the aquatic environment has become a significant issue of increasing importance (Huggett et al. 2003, Fent et al. 2006). Particularly non-steroidal anti-inflammatory drugs (NSAIDs), but also $\beta$-blockers, are among the substances detected in surface waters and sewage treatment plant effluents and are, due to their high volume of usage, considered an important pollutant group (Cleuvers 2005, Fent et al. 2006). In Sweden, the NSAID ibuprofen was found in sewage treatment plant effluents at concentrations up to $7.8 \mu \mathrm{g} \mathrm{l}^{-1}$ (Andersson et al. 2006). The mean surface water concentration of ibuprofen in Europe is $0.53 \mu \mathrm{g} \mathrm{l}^{-1}$ (Paxéus 2004), while it is lower in Swedish waters (1.7 to $5.6 \mathrm{ng} \mathrm{l}^{-1}$; Andersson et al. 2006). The $\beta$-blocker propranolol was found at levels of up to $0.59 \mu \mathrm{g} \mathrm{l}^{-1}$ in German surface waters (Ternes 1998). The detected concentrations of propranolol in the Baltic Sea are similar or slightly lower than in other parts of Europe (e.g. Hirsch et al. 1996, Maurer et al. 2007).
Pharmaceuticals are intended to have a biological effect, which makes them potentially harmful xenobiotics. Propranolol is a non-specific $\beta$-receptor antagonist which binds to both $\beta_{1}$ - and $\beta_{2}$-receptors (Alexander \& Wood 1987). Furthermore, propranolol has membrane-stabilising properties (Kim et al. 2003) and acts as a serotonin receptor antagonist (Alexander \& Wood 1987). NSAIDs inhibit the cyclooxygenase activity of prostaglandin $\mathrm{H}_{2}$ synthase, which catalyses the production of prostaglandins and thromboxanes (Nelson \& Cox 2005). The modes of action and effects of $\beta$-blockers and NSAIDs in nontarget organisms, especially invertebrates, and their route of uptake are not well understood (Cleuvers 2003, Fent et al. 2006, Owen et al. 2007).

Acute effects of propranolol and ibuprofen have been investigated using different organisms. Phytoand zooplankton seem to be more sensitive to propranolol than e.g. fish (Fent et al. 2006). In spite of this, most studies investigating chronic effects of propranolol and ibuprofen were performed with different fish species (Huggett et al. 2002, Fraysse et al. 2006). Thus, the chronic effects of these 2 substances have not been well investigated, and effect studies on littoral organisms in the immediate vicinity of most sewage treatment plants of the Baltic Sea have never been performed.

Here we compared the effects of 2 types of human pharmaceuticals, a $\beta$-blocker and an anti-inflammatory substance, on the grazers Gammarus spp. and the macroalga Fucus vesiculosus with the aim of broadening the knowledge about the potential risk of such contamination to littoral communities in the Baltic Sea and other brackish-water ecosystems. Behavioural and physiological endpoints (locomotor activity, habitat and predator recognition, feeding rate, chlorophyll fluorescence, primary production and respiration) were studied.

\section{MATERIALS AND METHODS}

\section{Test substances, sampling and experimental design}

Ibuprofen and propranolol were obtained from Sigma Aldrich. Ibuprofen was dissolved in dilute bisodium carbonate buffer, and the $\mathrm{pH}$ was adjusted to 7.1 by the addition of dilute phosphoric acid. Propranolol was dissolved in dilute phosphoric acid, and the $\mathrm{pH}$ was adjusted to 7.1 by the addition of bisodium carbonate solution. All solutions were prepared and diluted with buffer so that the final concentrations of sodium, phosphate and carbonate ions 
were identical. The use of buffers to dissolve the pharmaceuticals leads to no or insignificant adsorbtion to the surfaces of the exposure and experimental vessels (Palmgrén et al. 2006). A solvent control was used in the experiment and tested for different responses of the physiological measurements compared to the seawater control. No statistical difference was found between control treatments with and without solvent. The solvent control was used in the statistical analyses and in graphs. Concentrations were chosen to cover the range from environmentally relevant levels to observed effect concentrations from other studies. The nominal concentrations used of ibuprofen were 1, 1000 and $10000 \mu g \mathrm{l}^{-1}$, which are referred to as IL, IM and $\mathrm{IH}$, respectively, and those of propranolol were 100, 1000 and $5000 \mathrm{\mu g} \mathrm{l}^{-1}$, which are referred to as PL, PM and $\mathrm{PH}$, respectively. The corresponding measured concentrations of propranolol were $177 \pm 9,1436 \pm 72$ and $8347 \pm 417 \mu \mathrm{g}$ $\mathrm{l}^{-1}$ (mean $\pm \mathrm{CV}$, see Expt $\mathrm{C}$ below).

The study was run in 3 experiments (Fig. 1). In the first setup (A), animals were exposed individually in 9 replicates and feeding rate was measured (see measurement of feeding rate). In the second experiment (B), 8 replicates of animals were exposed

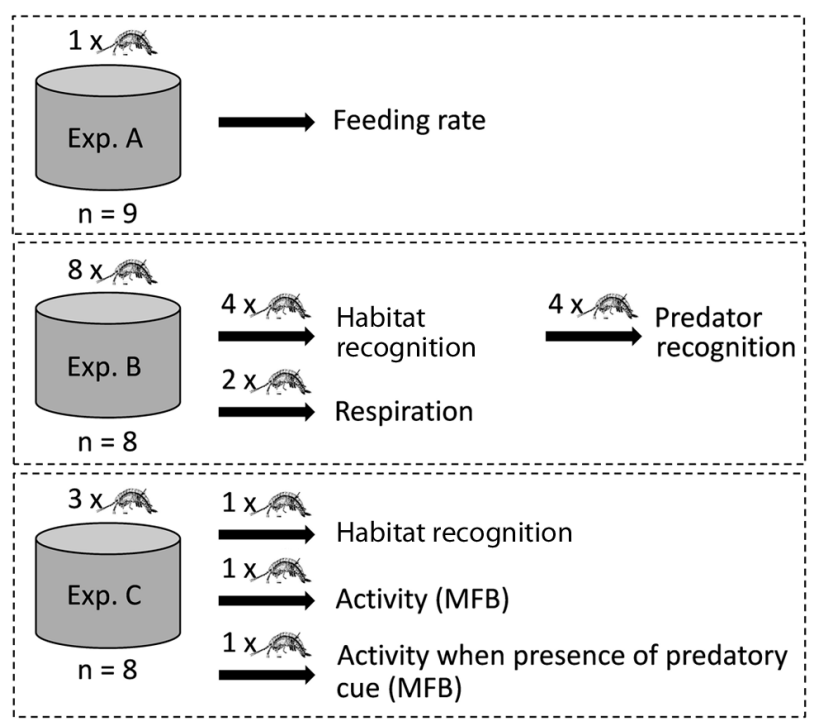

Fig. 1. Experimental setup of Expts A, B and C, illustrating the number of individual Gammarus spp. per replicate during the exposure phase, number of replicates and number of individuals used for specific endpoints. One tip (Expt A) or branch (Expts B and C) of Fucus vesiculosus was placed in each experimental chamber. In Expt $B$, the gross production to respiration (GP/R) ratio and chlorophyll fluorescence were measured on the algae. MFB: Multispecies Freshwater Biomonitor. The organisms were exposed to low, middle and high concentrations of: ibuprofen in Expts A and $\mathrm{B}_{i}$ propanolol in Expts $\mathrm{A}, \mathrm{B}$ and $\mathrm{C}$ in aerated plastic beakers filled with $1000 \mathrm{ml}$ of natural seawater, each containing 8 individuals and a branch of Fucus vesiculosus. After 7 d, 4 individuals from each replicate were used for the habitat and predator recognition tests. The animals and algae were then further exposed for $2 \mathrm{~d}$ before physiological variables were measured. Exposure and physiology measurements (except determination of swimming activity) were performed in a climate chamber to maintain natural field conditions. Exposure beakers were arranged randomly to avoid the influence of potential gradients in the room, and all experiments were performed with blind labelling to avoid subjectivity of the experimenter. None of the individuals were used for more than 1 test, with the exception of the predator recognition test, which was performed directly after the habitat recognition test with the same individuals. Pilot tests were performed for the behavioural endpoints before the experiments were conducted to get information about e.g. suitable numbers of individuals and observation durations (data not shown). In the third experiment (C), the effects of propranolol on behaviour were explored by using the Multispecies Freshwater Biomonitor (MFB $\left.{ }^{\mathrm{TM}}\right)$. In Expt C, 8 replicates were used, each containing 3 individuals. One individual from each replicate was used for MFB measurements. Water samples for chemical analyses of propranolol were collected and analysed during Expt C (see below).

For all 3 experiments, the test organisms Gammarus spp. and Fucus vesiculosus as well as natural seawater (salinity 6 psu and filtered through a sand filter) were collected at the Askö Laboratory, Stockholm University Marine Research Centre, Baltic Sea, Sweden. Gammarus spp. were sampled with a net from 1.5 to $4 \mathrm{~m}$ depth. $F$. vesiculosus was collected by hand close to the shoreline at $0.5 \mathrm{~m}$ depth. Amphipods of approximately the same size $(15 \mathrm{~mm})$ were sorted out and allowed to acclimatise for $12 \mathrm{~h}$ in aerated natural sea water before the exposure experiments started. After the experiments, a subsample was examined under a stereo microscope to determine the species composition. In Expts A and B, G. oceanicus was the clearly dominating species and comprised more than $95 \%$ of the subsample. The amphipods in Expt $\mathrm{C}$ were collected at a later occasion at the same site using the same methods, but in these samples, G. zaddachi was the dominating species. This seasonal variation in species dominance within Gammarus is normal in the littoral zone of the Baltic Sea (Kolding \& Fenchel 1979). We assumed that the 
Gammarus spp. used in the experiments had the same species composition as in the subsamples. Hereafter, the organisms are denoted Gammarus spp. and F. vesiculosus. After collection and sorting, all organisms were transported to climate chambers at Stockholm University and kept at temperature and light regimes close to the naturally occurring regime at the time of collection $\left(10\right.$ to $11^{\circ} \mathrm{C}, 10 \mathrm{~h}: 14$ $\mathrm{h}$ light:dark) during the acclimatisation and experiments. The branches of $F$. vesiculosus were cleared as far as possible from epibiota before they were used in the experiment.

\section{Measurements of Gammarus spp.}

\section{Experiment A}

To estimate feeding rate, Gammarus spp. were exposed individually in plastic beakers containing $100 \mathrm{ml}$ of constantly aerated natural seawater. Equally sized tips of Fucus vesiculosus (ca. $1 \times 1 \mathrm{~cm}$ ) were dried with cellulose paper, weighed and added to each beaker; 9 blanks were used, which contained only algae to control for leaf weight change due to leaching. After $6 \mathrm{~d}$ of exposure and grazing, the pieces of algae were removed, dried and weighed in the same manner as prior to the experiment. Animals were dried at $60^{\circ} \mathrm{C}$ for $24 \mathrm{~h}$ and weighed. Feeding rate (mg F. vesiculosus wet weight per mg Gammarus spp. dry weight per day) was calculated using Eq. 1 (Maltby 1992):

$$
\text { Feeding rate }=\frac{L_{1} \times C_{1}-L_{2}}{W \times t}
$$

where $L_{1}$ is initial and $L_{2}$ is final weight of $F$. vesiculosus pieces in mg, $W$ is the dry weight of Gammarus spp. (mg), $t$ is the exposure time in days, and $C_{1}$ is a correction factor for weight change due to passive leaching of the algae, defined by Eq. 2:

$$
C_{1}=\frac{\Sigma L_{b} / L_{a}}{n}
$$

where $L_{a}$ and $L_{b}$ refer to the initial and final wet weights, respectively, of the 9 (n) F. vesiculosus pieces of the control treatment for leaching processes.

\section{Experiment B}

In Expt B, 4 individuals from each replicate were chosen after $7 \mathrm{~d}$ of exposure and moved to other small glass aquaria $(15 \times 7 \times 7 \mathrm{~cm})$ with a branch of
Fucus vesiculosus in 1 corner. Each Gammarus spp. specimen was placed in the corner opposite that with the Fucus branch. The time needed for each individual to find the habitat (determined by passing a line when approaching the Fucus branch in the corner) was then investigated.

In the predator recognition test, the same experimental setup as in the habitat recognition test was used. To simulate the presence of a predator, $1.25 \mathrm{ml}$ unfiltered water from an aquarium with 400 threespined sticklebacks Gasterosteus aculeatus was applied to the predator recognition aquarium in the corner opposite the Fucus branch. The predator avoidance response was defined as a swimming response within $15 \mathrm{~s}$ after the application of stickleback water.

Respiration was measured after $9 \mathrm{~d}$ of exposure. Two of the individuals from each exposure beaker were selected and kept individually in $20 \mathrm{ml}$ beakers during the respiration measurement. At intervals of approximately $3 \mathrm{~h}$, dissolved oxygen in the water was measured twice with an $\mathrm{O}_{2}$ sensor (Unisense) connected to a pA meter (PA 2000, Unisense). Plastic foil was placed on the water surface of each beaker between the measurements to avoid diffusion of dissolved oxygen over the water surface. Mean respiration of both individuals was calculated for each exposure beaker. Change in dissolved oxygen concentration caused by algal production was corrected for by 6 blank beakers with only water. The mean value of the 2 individuals from each aquarium was used in the statistical analyses.

\section{Experiment C}

After $7 \mathrm{~d}$ of exposure, 2 tests were performed. In Test 1, time for the Gammarus spp. to reach their habitat was estimated in a similar way as in Expt B, except that only 1 individual from each replicate was used. In the second test, effects from the combination of propranolol and predator cues were measured by using the MFB. The MFB equipment is based on the quadruple impedance conversion technique to record online the behavioural patterns of animals (Gerhardt et al. 1994). The MFB has been applied successfully in ecotoxicological studies with a multitude of species but was originally developed for amphipods (Gerhardt et al. 1998, De Lange et al. 2006, Macedo-Sousa et al. 2007). During the measurement, each amphipod was placed in a plastic chamber $(7.5 \mathrm{~cm}$ in length and $3.5 \mathrm{~cm}$ in diameter, netting sides with mesh size of $0.1 \mathrm{~mm}$ ) with 2 pairs 
of electrodes inside along the wall. The animal can move freely inside the measuring chamber, which is situated in a $1 \mathrm{l}$ aquarium without aeration to avoid interference with the electrical signal. In the measuring chamber, 1 pair of electrodes produces a constant alternating current, while the other pair of electrodes measures changes in the electrical field produced by the animal's movements (e.g. swimming, ventilation, feeding; Gerhardt et al. 1998, Gerhardt 2007, Macedo-Sousa et al. 2007). These movements generate specific frequencies, and the MFB software, through a stepwise discrete Fourier transformation, can estimate the percentage of time spent at each frequency. In the case of freshwater amphipods, low frequencies (from 0.5 to $2.0 \mathrm{~Hz}$ ) are related to swimming behaviour and high frequencies (from 2.5 to $8.5 \mathrm{~Hz}$ ) to ventilation (Gerhardt et al. 2007). In addition to activity, the effect of predator cues on activity was also studied in this experiment, simulated by adding water from the same type of fish tank as in Expt B. An acclimation period of 20 min was allowed before the measurements started and continued for $2 \mathrm{~h}$. The average percent of the activity in the upper and lower frequency bands was used in the further analyses.

\section{Measurements of Fucus vesiculosus (Experiment B)}

Fucus vesiculosus branches were moved from the exposure beakers to $380 \mathrm{ml}$ beakers were the gross primary production (GP) to respiration (R) ratio (GP/R) was measured. Net oxygen production (mg $\mathrm{O}_{2} \mathrm{~g}^{-1} \mathrm{dw} \mathrm{h} \mathrm{h}^{-1}$ ) and respiration $\left(\mathrm{mg} \mathrm{O}_{2} \mathrm{~g}^{-1} \mathrm{dw} \mathrm{h}^{-1}\right)$ were estimated as the change in dissolved oxygen concentration per unit time, similarly as for the Gammarus spp. Respiration was estimated during dark conditions prior to the production (P) measurement, which was established in light. As the algae were assumed to produce oxygen only during the light conditions, but respire during both light and dark conditions, GP was calculated as the sum of $\mathrm{P}$ and $\mathrm{R}$.

Chlorophyll fluorescence of Fucus vesiculosus was estimated using a pulse amplitude modulated chlorophyll fluorometer (Diving PAM, Waltz). Each sample was irradiated for $0.8 \mathrm{~s}$ at a constant distance of $10 \mathrm{~mm}$ from the leaf thallus, and the fluorescence was measured. An average for every sample was determined from 10 measurements. The quantum yield of electron transfer in PSII was determined as the ratio of variable fluorescence and maximum fluorescence $\left(\Delta \mathrm{F} / \mathrm{Fm}^{\prime}\right)$.

\section{Chemical analysis}

Samples were analysed using liquid chromatography (LC) with mass spectrometry (MS) detection. The LC system was composed of 2 Shimadzu LC-10AD pumps, a SIL-10Avp autosampler and an SCL-10Avp controller unit. A linear gradient was used between $10 \%$ and $90 \%$ acetonitrile in $0.2 \%$ ammonium acetate buffer solution starting at $0.5 \mathrm{~min}$ and finishing at $7.5 \mathrm{~min}$. A $3 \mathrm{~min}$ equilibration time was used at the end of each run. The total flow rate was $100 \mu \mathrm{min}^{-1}$. The LC column used was a $50 \times 2.1 \mathrm{~mm}$ ACE C18 column packed with $3 \mu \mathrm{m}$ diameter particles. The mass spectrometer used was a Thermo Finnigan LCQ Deca Classic run in positive ion mode. Quantification was performed using deuterated propranolol as a surrogate standard. The following parent and daughter ions were used: $\mathrm{m} / \mathrm{z}=260$ and $\mathrm{m} / \mathrm{z}=184$ for propranolol and $\mathrm{m} / \mathrm{z}=267$ and $\mathrm{m} / \mathrm{z}=190$ for deuterated propranolol. Formic acid (10 $\mu$ l of a $10 \%$ solution) and surrogate standard (15 $\mu \mathrm{l}$ of deuterated propranolol in methanol) were mixed with $975 \mu$ of sample solution. The solution was filtered through $0.45 \mu \mathrm{m}$ nylon syringe filters prior to analysis.

\section{Statistical analysis}

Data were analysed by a general linear model (GLM). In Expts A and B, pharmaceutical treatment was used as a fixed factor, while in Expt C, concentration of propranolol and presence of predator cues and the interaction between these were analysed. Statistical tests were performed for relevant contrasts between treatment groups (concentration, pharmaceutical, predator presence) as well as dose response relationships. Results from the statistical analyses are presented both corrected for multiplicity according to Holm (1979) and uncorrected in Supplement 1 at www.int-res.com/articles/suppl/b014p029_supp.pdf. Statistical analyses were performed using SAS v. 9.2.

\section{RESULTS}

\section{Gammarus spp.}

The average mortality in the treatments was less than $10 \%$ and was not significantly different from the control $(6 \pm 3 \%$, mean $\pm \mathrm{SE})$ in any other treatment. Therefore, exposure durations and concentrations were assumed relevant to investigate sublethal effects. No significant effects of ibuprofen were 


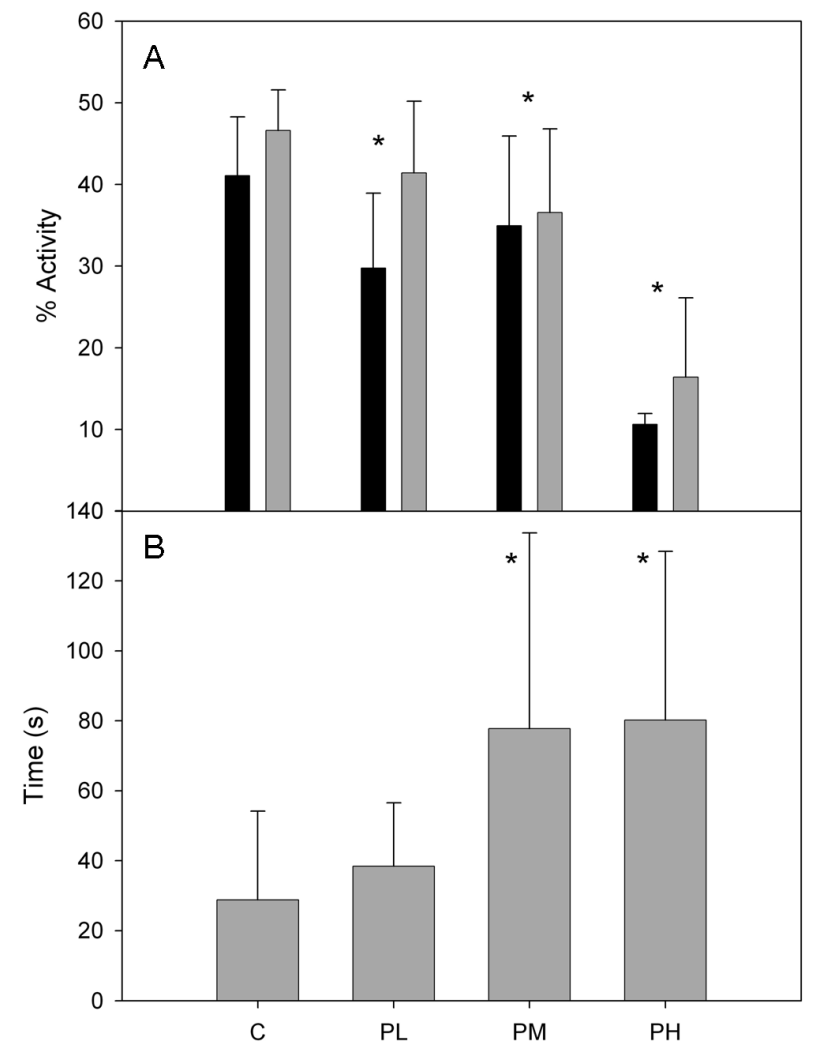

Fig. 2. Gammarus spp. (A) Mobility activity (black bars) and respiratory activity (grey bars) measured with the Multispecies Freshwater Biomonitor (MFB). (B) Time Gammarus spp. needed to find their habitat (Fucus vesiculosus) in the presence of predator cues. All values represent the mean of 8 replicates ( $\mathrm{n}=1$ individual) $\pm \mathrm{SEM}$ after $7 \mathrm{~d}$ exposure to the different treatments C: control, PL/PM/PH: propranolol at 100, 1000 and $5000 \mu \mathrm{g} \mathrm{l}^{-1}$, respectively. ${ }^{*}$ significant differences from the control treatment

observed, but physiolological data of ibuprofen are graphically displayed (see Figs. 3 \&4).

\section{Behavioural experiments}

Gammarus spp. exposed to propranolol decreased their activity at the lower frequencies, which represent movements when measured with the MFB $(p<$ 0.0001, Expt $C_{i}$ Fig. 2; Table S1A in Supplement 1 at www.int-res.com/articles/suppl/b014p029_supp.pdf). There was no effect at the higher frequencies, which represent respiration. The presence of predator cues increased the activity in all treatments $(p<0.05$, Expt $C_{i}$ Fig. 2), although no interaction between predator presence and pharmaceutical concentrations was found. Responses of predator cue additions were significantly different from the treatments without predator cues (Table S1A). The predator response study in Expt B showed the same tendency, although no significant result was obtained after multiplicity correction (Table S2). The mean percentage of Gammarus spp. from the control treatment reacting to predator scent was $34 \pm 8 \%$, and amphipods at the highest concentration showed the least reaction $(19 \pm$ $10 \%$, i.e. $55 \%$ of control; Expt B). The time spent to reach habitat (Fucus vesiculosus) increased with increasing concentrations of propranolol $(\mathrm{p}<0.01$, Expt $C_{i}$ Fig. 2, Table S3). Especially individuals exposed to the highest concentrations tended not to search as actively as those in the control and the low concentration treatments (Expt C). No significant effects could be detected in Expt B.

\section{Physiology}

The feeding rate of organisms in the control treatment was $0.46 \pm 0.09 \mathrm{mg}$ Fucus wet weight per $\mathrm{mg}$ dry weight of Gammarus spp. per day (Fig. 3). The feeding rate in the propranolol treatment was twice as high compared to the ibuprofen treatment and the control, i.e. a significant difference between pharma-
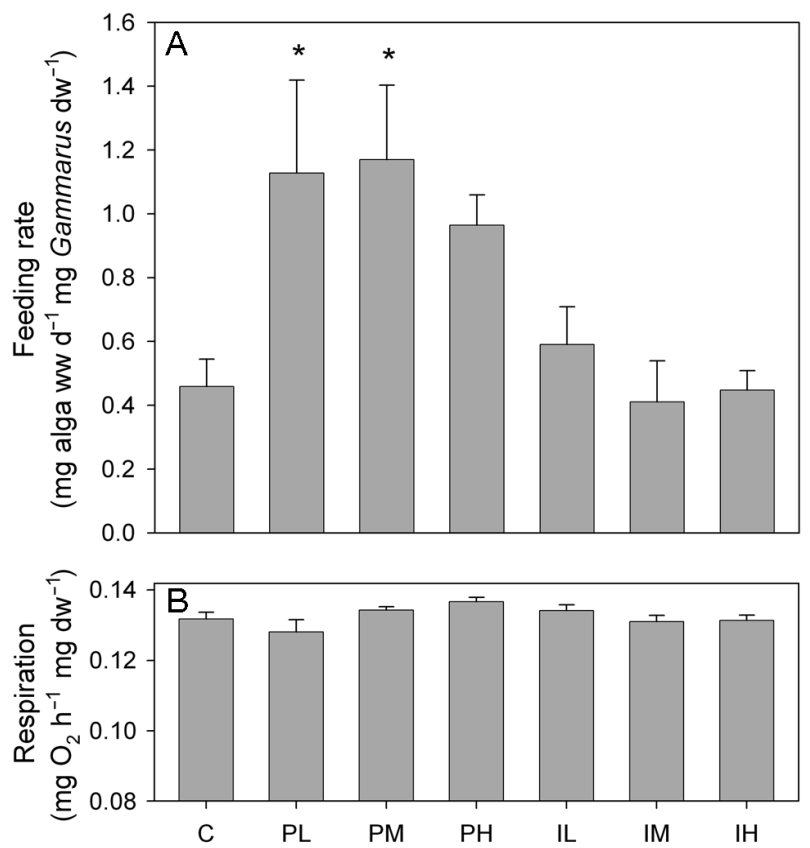

Fig. 3. Gammarus spp. (A) Feeding rate after 7 d exposure to the different treatments. Values represent the mean of 9 animals \pm SEM. (B) Mean respiration after $7 \mathrm{~d}$ exposure to the different treatments. C: control, PL/PM/PH: propranolol at 100, 1000 and $5000 \mathrm{\mu g} \mathrm{l}^{-1}$; IL/IM/IH: ibuprofen at 1, 1000 and $10000 \mu \mathrm{g} \mathrm{l} \mathrm{l}^{-1}$. Values represent the mean of 8 replicates $(\mathrm{n}=2$ individuals) \pm SEM. * significant differences from the control treatment. ww: wet weight; dw: dry weight 
ceuticals $\left(p<0.001\right.$, Expt $A_{\text {; }}$ Table S4A). Both the overall feeding rate in propranolol treatments, as well as each individual propranolol concentration was higher than the control $\left(\mathrm{p}<0.01\right.$, Expt $\mathrm{A}_{i}$ Table S4). There was no dose-response relationship.

The control had a mean respiration of $0.13 \pm$ $0.003 \mathrm{mg} \mathrm{O}_{2} \mathrm{~h}^{-1} \mathrm{mg}^{-1}$ dry weight Gammarus spp. (Fig. 3). For ibuprofen, amphipods held at the lowest concentration $\left(1 \mu \mathrm{g} \mathrm{l}^{-1}\right)$ showed the largest elevation compared to the controls, where the respiration increased by approximately $21 \%$. Both respiration and feeding rate showed a similar pattern, and with the exception of 1 outlier (PL treatment), there was a linear relationship between respiration and feeding rate (Fig. S1, Table S5 in Supplement 2 at www.intres.com/articles/suppl/b014p029_supp.pdf).

\section{Fucus vesiculosus}

There were significant differences in chlorophyll fluorescence between exposure to different pharmaceuticals ( $p<0.0001$, Expt B; Fig. 4, Table S6A). The response in the highest concentration of propranolol and the control differed significantly $(\mathrm{p}<0.001$, Expt $B_{i}$ Table S6B). Propranolol also affected the GP/R ratio and its components. There was a significant difference between the 2 pharmaceuticals $(p<0.001$, Expt B; Fig. 4, Table S7A), and there was a significant dose relationship for propranolol $(\mathrm{p}<0.001$, Expt $\mathrm{B}$; Table S7A). The GP/R ratio in $F$. vesiculosus exposed to the highest concentration of propranolol was significantly lower than the control $(p>0.001$, Expt $B$; Table S7B). Both respiration and gross production showed a similar pattern as the GP/R ratio (Tables S8 \& S9).

\section{DISCUSSION}

\section{Behavioural effects}

Behavioural endpoints can be more sensitive to contaminants than other endpoints (Warner et al. 1966), leaving behavioural studies potentially more ecologically relevant. Mobility is related to a number of important inter- and intraspecific interactions such as reproduction, food acquisition and predator avoidance. Because of their importance for marine food webs, alterations of locomotor activity in amphipods by environmental contaminants can have important ecological consequences (Wallace \& Estephan 2004). In the present study, mobility was measured by the MFB in the form of activity, e.g. swimming. The activ-
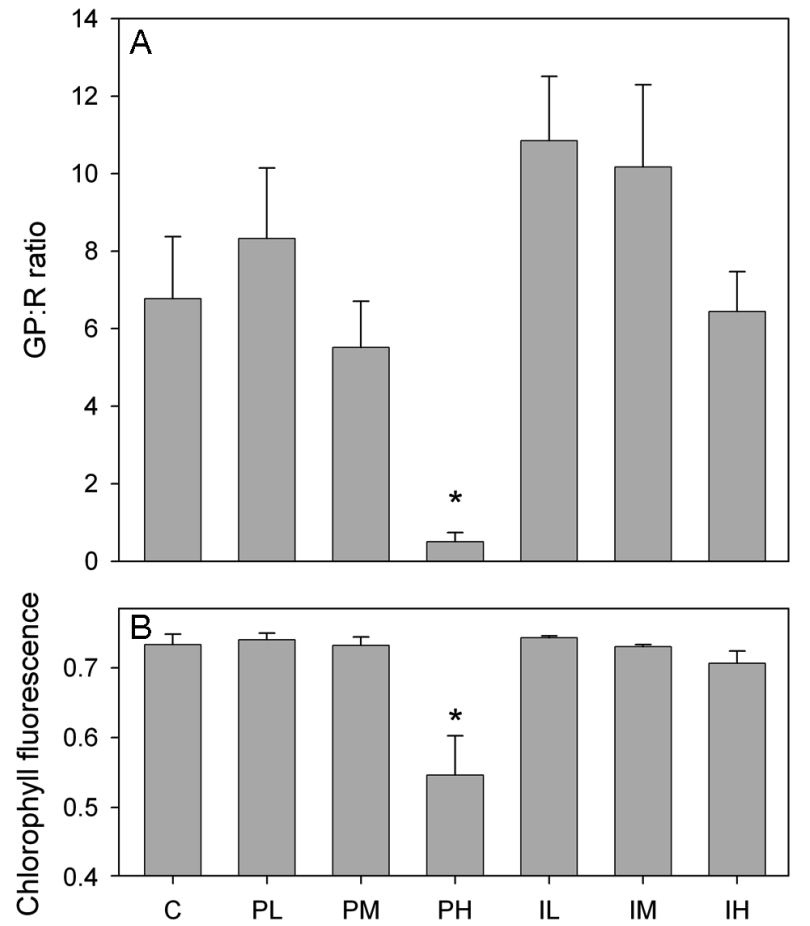

Fig. 4. Fucus vesiculosus. (A) Gross production to respiration (GP/R) ratio. (B) Chlorophyll fluorescence after $7 \mathrm{~d}$ exposure to the different treatments. C: control, PL/PM/PH: propranolol at 100, 1000 and $5000 \mu \mathrm{g} \mathrm{l}^{-1}$; IL/IM/IH: ibuprofen at 1, 1000 and $10000 \mu \mathrm{g} \mathrm{l}^{-1}$. Values represent the mean of 8 replicates \pm SEM. ${ }^{*}$ significant differences from the control treatment

ity decreased with increasing concentrations of propranolol. The increase in time spent to find habitat with increasing concentrations of propranolol in Expt C also supports the results obtained by the MFB. These results are further supported by a recent study by Sun et al. (2011), which showed that propranolol significantly decreased locomotor activity in mice. In high-dose exposure experients on Daphnia magna, both $\beta$-blockers and NSAIDs increased heart rate and induced high levels of stress proteins (Dzialowski et al. 2006, Haap et al. 2008). Low concentrations of ibuprofen increased locomotion in Gammarus pulex (De Lange et al. 2006), whereas all concentrations of ibuprofen used in our study yielded similar results as in the controls. The difference in exposure level between the present study and De Lange et al. (2006) might explain the lack of difference between control and exposed individuals in this experiment.

Habitat provides a refuge from predation, and the ability to recognise the scent of a predator, and thereby avoid direct interactions, is essential for the survival of an organism. To identify and locate food, habitats and predators, crustaceans rely on a combination of sophisticated chemosensory systems (Derby 
\& Sorensen 2008). If these systems are disturbed by xenobiotics, the consequences could be severe, especially for Baltic Sea Gammarus spp., since their habitat, the stands of Fucus and its epibiota, are also their main food source. In Expt $C$, the presence of predator cues increased activity in both control organisms and those exposed to propranolol. However, individuals exposed to propranolol could not compensate for the reduction in activity caused by the pharmaceutical. A similar, albeit non-significant, tendency was also obtained in Expt B. G. pulex is very sensitive to predator cues (Åbjörnsson et al. 2000), and the presence of a predator also affects habitat choice of the prey (Zamzow et al. 2010). Although the highest concentrations of pharmaceuticals used in the present study were far from the concentrations found in situ, the results from the present study are an alarm signal indicating reduction in activity of an essential function.

There are 2 important groups of signal substances released in predator-prey interactions. The kairomones are peptides released by predators, which allow prey to detect and evade a predator. A second group includes the signals that are released from disturbed prey, which consist of urinary ammonia (Kiesecker \& Blaustein 1997). Wisenden et al. (1999) demonstrated that aquatic organisms also show antipredator responses from injured conspecifics, a third class of cues. The response to these signals can either be fixed, i.e. all individuals respond irrespective of whether they have been previously exposed, or induced, which means that a naive individual will not respond or will show a weaker response than an experienced individual. Effects on predator recognition have previously been demonstrated in fish and tadpoles exposed to acidification, pesticides and heavy metals (Scott et al. 2003, Mandrillon \& Saglio 2007). Scott et al. (2003) also found that the effect of the contaminant on behaviour was only present after waterborne exposure. To our knowledge, no experiments prior to this have been performed on the effects of pharmaceuticals on predator-prey interactions.

\section{Physiological effects}

Feeding rate is reported to be decreased by certain substances, e.g. cadmium (Felten et al. 2008), thereby reducing the individual's scope for growth or reproduction if energy expenditure remains constant (Maltby 1992). Surprisingly, feeding rates were significantly increased by approximately 2.5 -fold at concentrations of 100 and $1000 \mu \mathrm{g} \mathrm{l}^{-1}$ propranolol, compared to controls and Gammarus spp. exposed to ibuprofen. Respiration is essential for organisms, and crustacean gills are crucial for osmotic and ionic regulation, acid-base balance and respiration. These gills are sensitive primary targets for a wide range of xenobiotics that are present in the aquatic environment (Felten et al. 2008). The respiration rate, considered an estimator of the energy expenditure of an organism due to metabolism (Maltby 1992), was elevated by propranolol, as respiration increased with increasing propranolol concentration. Taking this into account, Gammarus spp. seem to compensate for the higher energy demand by elevating their rate of feeding (Fig. S1). This could have unforeseen consequences for the algae on which Gammarus spp. feed, and will probably impact inter- and intraspecific interactions such as reproduction or predator avoidance. The pattern for Gammarus spp. exposed to ibuprofen was similar but not significant; the lowest level showed the highest increase in respiration by approximately $21 \%$, which is supported by $22 \%$ increased feeding rate. More pronounced effects of propranolol compared to ibuprofen and effects exerted by concentrations in similar ranges as those used in this experiment have been shown to negatively influence e.g. the byssus thread strength, byssus thread abundance and physiology of blue mussels Mytilus edulis (Ericson et al. 2010, L. Kumblad et al. unpubl.), as well as the physiology of Gammarus spp. and Fucus vesiculosus (Oskarsson et al. in press).

The GP/R ratio of the exposed alga showed that both pharmaceuticals resulted in a significant negative dose-response pattern. However, even if the negative trend is similar between the substances, Fucus vesiculosus exposed to low concentrations of ibuprofen had a comparatively higher GP/R ratio than the controls, while those exposed to the low concentration of propranolol resembled the controls. In F. vesiculosus exposed to ibuprofen, respiration had the largest impact on GP/R. The highest concentration of propranolol had a strong impact on both respiration and production. Effects of this treatment could also be visually observed, as the branches exposed to the highest propranolol concentration turned darker and redder throughout the exposure. The water in these treatments also became discoloured. Oskarsson et al. (in press) observed a similar response in F. vesiculosus.

\section{General implications}

The present study showed sublethal effects of the $\beta$-blocker propranolol on physiological and behav- 
ioural parameters in Gammarus spp. Levels of propranolol in surface waters have been measured within a range of 0.1 to $0.59 \mathrm{\mu g} \mathrm{l}^{-1}$ (Ternes 1998, Cleuvers 2005, Fent et al. 2006). At the lowest concentration, the physiological responses in the present study were stimulated compared to controls, while at the highest dose, reduced responses were demonstrated. Non-linear responses are common in experiments testing pharmaceuticals and other emerging substances (e.g. Calabrese \& Baldwin 2001, De Lange et al. 2006, 2009, Eriksson Wiklund et al. 2012 in press). Although the measured effect concentrations are higher than environmental concentrations, the traditional predicted environmental concentrations (PEC) to predicted no-effect concentration (PNEC) ratio approach in risk assessment would indicate a high relevance to the environment (Cleuvers 2005). If measured levels in surface waters $(0.1$ to $0.59 \mu \mathrm{g} \mathrm{l}^{-1}$ ) are defined as PECs, and the PNEC is calculated by dividing the lowest level of propranolol which showed effects $\left(100 \mu \mathrm{g} \mathrm{l}^{-1}\right)$ by an assessment factor of $1000\left(0.1 \mathrm{~g} \mathrm{l}^{-1}\right)$, which is often the case in environmental risk assessments, the PEC/PNEC ratio would range within 1 and 5, which is an indication that further testing of the substance is required (European Communities 2003). Besides, organisms in the aquatic environment are usually chronically exposed throughout their life cycle and exposed to complex mixtures, which could result in different mixture effects, e.g. potentiation or synergistic responses. Furthermore, the $\beta$-blocker substances atenolol and metoprolol are more frequently used and are found in higher concentrations than propranolol in the aquatic environment (Cleuvers 2005, Fent et al. 2006) and should therefore be further investigated as they possibly have effects similar to propranolol. Massarsky et al. (2011) also stated that further studies of these substances require longer exposures and additional endpoints.

Gammarus spp. are considered key species since they are abundant grazers in the Baltic Sea, strongly associated with Fucus vesiculosus and represent an important link from primary producers to secondary consumers in the coastal zone. The Baltic Sea has a low biodiversity and is therefore a very sensitive ecosystem. The 2.5-fold increase in feeding rate caused by the low and medium concentrations of propranolol in the present study implies elevated grazing rates in the field. Several ecologically relevant implications, e.g. changes in populations of $F$. vesiculosus, the grazers which feed on it and other organisms living in this habitat, are related to this from a short-term perspective. Alterations in the food web and energy cycle could be potential effects over the long term. In combination with the reduced reaction to predator cues, the enhanced energy need is unfavourable for organism survival and fitness. Effects on fitness, feeding and respiration of Gammarus spp. and GP/R-ratio and chlorophyll fluorescence in $F$. vesiculosus observed in this study may have an impact on growth and reproduction. Consequently, this may have an effect at the population level of these particular species, as well as on the species they interact with. Since different species tend to differ in tolerance, unexpected indirect and cascade effects can occur which eventually may have implications on community as well as ecosystem scales.

Acknowledgements. We thank M. Brinkmann, E. Eklund, S. Ericsson, J. Gustavsson and K. Lisslö for helping us perform the experiment, B. Borg (Department of Zoology, Stockholm University) for supplying water from stickleback aquaria and B. Eklund and the personnel at the Askö Field Station for assistance during sampling.

\section{LITERATURE CITED}

Åbjörnsson K, Dahl J, Nyström P, Brönmark C (2000) Influence of predator and dietary chemical cues on the behavior and shredding efficiency of Gammarus pulex. Aquat Ecol 34:379-387

Alexander BS, Wood MD (1987) Stereoselective blockade of central $\left[{ }^{3} \mathrm{H}\right] 5$-hydroxytryptamine binding to multiple sites (5-HT1A, 5-HT1B, and 5-HT1C) by mianserin and propranolol. J Pharmacol 39:664-666

Andersson J, Woldegiorgis A, Remberger M, Kaj L and others (2006) Results from the Swedish national screening programme - subreport 1, IVL report B1689. Stockholm Arrontes J (1999) On the evolution of interactions between marine mesoherbivores and algae. Bot Mar 42:137-155

Calabrese EJ, Baldwin LA (2001) The frequency of Ushaped dose responses in the toxicological literature. Toxicol Sci 62:330-338

Cleuvers M (2003) Aquatic ecotoxicology of pharmaceuticals including the assessment of combination effects. Toxicol Lett 142:185-194

Cleuvers M (2005) Initial risk assessment for three $\beta$-blockers found in the aquatic environment. Chemosphere 59: 199-205

Clotfelter ED, Bell AM, Levering KR (2004) The role of animal behaviour in the study of endocrine-disrupting chemicals. Anim Behav 68:665-676

> De Lange HJ, Lürling M, Van den Borne B, Peeters ETHM (2005) Attraction of the amphipod Gammarus pulex to water-borne cues of food. Hydrobiologia 544:19-25

> De Lange HJ, Noordoven W, Murk AJ, Lürling M, Peeters ETHM (2006) Behavioural responses of Gammarus pulex (Crustacea: Amphipoda) to low concentrations of pharmaceuticals. Aquat Toxicol 78:209-216

De Lange HJ, Peeters ETHM, Lürling M (2009) Changes in ventilation and locomotion of Gammarus pulex (Crustacea, Amphipoda) in response to low concentrations of pharmaceuticals. Hum Ecol Risk Assess 15:111-120 
Derby CD, Sorensen P (2008) Neural processing, perception, and behavioral responses to natural chemical stimuli by fish and crustaceans. J Chem Ecol 34:898-914

> Dzialowski EM, Turner PK, Brook BW (2006) Physiological and reproductive effects of beta adrenergic receptor antagonists in Daphnia magna. Arch Environ Contam Toxicol 50:503-510

> Ericson H, Thorsén G, Kumblad L (2010) Physiological effects of diclofenac, ibuprofen and propranolol on Baltic Sea blue mussels. Aquat Toxicol 99:223-231

Eriksson Wiklund AK, Breitholtz M, Bengtsson BE, Adolfsson Erici M (2012) Sucralose: an ecotoxicological challenger? Chemosphere 86:50-55

European Communities (2003) Institute for Health and Consumer Protection - European Chemicals Bureau, Technical Guidance Document on Risk Assessment in support of Commission Directive 93/67/EEC on Risk Assessment for new notified substances; Commission Regulation (EC) No 1488/94 on Risk Assessment for existing substances; Directive 98/8/EC of the European Parliament and of the Council concerning the placing of biocidal products on the market - Part I, II, III and IV - European Commission Joint Research Centre, EUR 20418

Felten V, Charmantier G, Monsa R, Geffard A and others (2008) Physiological and behavioural responses of Gammarus pulex (Crustacea: Amphipoda) exposed to cadmium. Aquat Toxicol 86:413-425

> Fent K, Weston AA, Caminada D (2006) Ecotoxicology of human pharmaceuticals. Aquat Toxicol 76:122-159

> Fraysse B, Mons R, Garric J (2006) Development of a zebrafish 4-day embryo-larval bioassay to assess toxicity of chemicals. Ecotoxicol Environ Saf 63:253-267

> Gerhardt A (1995) Monitoring behavioural responses to and effects of metals in Gammarus pulex (Crustacea) with impedance conversion. Environ Sci Pollut Res 2:15-23

- Gerhardt A (1996) Behavioural early warning responses to polluted surface water performance of Gammarus pulex L. (Crustacea) and Hydropsyche angustipennis Curtis (Insecta) to a complex industrial effluent. Environ Sci Pollut Res 3:63-67

Gerhardt A (1999) Recent trends in online biomonitoring for water quality control. In: Gerhardt A (ed) Biomonitoring of polluted water. Reviews on actual topics. Environmental Research Forum Series Vol 9. Trans Tech Publications, Zürich, p 95-118

> Gerhardt A (2007) Aquatic behavioral ecotoxicologyprospects and limitations. Hum Ecol Risk Assess 13: 481-491

Gerhardt A, Clostermann M, Fridlund B (1994) Monitoring of behavioural patterns of aquatic organisms with an impedance conversion technique. Environ Int 20:209-219

Gerhardt A, Carlsson A, Ressemann C, Stich KP (1998) New on line biomonitoring system for Gammarus pulex (L) (Crustacea): in situ test below a copper effluent in south Sweden. Environ Sci Technol 32:150-156

> Gerhardt A, Janssens de Bisthoven L, Penders E (2003) Quality control of drinking water from the River Rhine (Netherlands) with the Multispecies Freshwater Biomonitor. Aquat Ecosyst Health Manag 6:159-166

- Gerhardt A, De Bisthoven LJ, Soares AMV (2005) Evidence for the stepwise stress model: Gambusia holbrooki and Daphnia magna under acid mine drainage and acidified reference water stress. Environ Sci Technol 39:4150-4158

Gerhardt A, Kienle C, Allan IJ, Greenwood R and others (2007) Biomonitoring with Gammarus pulex at the
Meuse (NL), Aller (GER) and Rhine (F) rivers with the online Multispecies Freshwater Biomonitor ${ }^{\circledR}$. J Environ Monitor 9:979-985

> Haap T, Triebskorn R, Kohler HR (2008) Acute effects of diclofenac and DMSO to Daphnia magna: immobilisation and hsp70-induction. Chemosphere 73:353-359

> Hirsch M, Bar J, Bott-Kanner G, Kaplan B, Fuchs J, Ovadia J (1996) Effect of the beta-adrenergic blocker pindolol on platelet function in chronic hypertensive pregnancy. Hypertens Pregnancy 15:193-202

Holm S (1979) A simple sequential rejective multiple test procedure. Scand J Stat 6:65-70

> Huggett DB, Brooks BW, Peterson B, Foran CM, Schlenk D (2002) Toxicity of selected beta adrenergic receptorblocking pharmaceuticals ( $\beta$-blockers) on aquatic organisms. Arch Environ Contam Toxicol 43:229-235

> Huggett DB, Khan I, Allgood J, Foran C, Schlenk D (2003) Determination of beta-adrenergic receptor blocking pharmaceuticals in United States wastewater effluent. Environ Pollut 121:199-205

Kautsky L, Kautsky N (2000) The Baltic Sea, including Bothnian Sea and Bothnian Bay. In: Sheppard CRC (ed) Seas at the millenium: an environmental evaluation. Elsevier Science, Amsterdam, p 1-14

Kautsky H, Kautsky L, Kautsky N, Lindblad C (1992) Studies on the Fucus vesiculosus community in the Baltic Sea. Acta Phytogeogr Suecia 78:33-48

Khlebovich VV (1990) Some physico-chemical and biological phenomena in salinity gradient. Limnologica 20:5-9

Kiesecker JM, Blaustein AR (1997) Population differences in responses of red-legged frogs (Rana aurora) to introduced bullfrogs. Ecology 78:1752-1760

Kim H, Jeong K, Lee S, Jung S (2003) Molecular modeling of the chiral recognition of propranolol enantiomers by a $\beta$-cyclodextrin. Bull Korean Chem Soc 24:95-98

Kolding S, Fenchel TM (1979) Coexistence and life cycle characteristics of five species of the amphipod genus Gammarus. Oikos 33:323-327

Macedo-Sousa JA, Pestana JLT, Gerhardt A, Nougeira AJA, Soares AMVM (2007) Behavioural and feeding responses of Echinogammarus meridionalis (Crustacea, Amphipoda) to acid mine drainage. Chemosphere 67:1663-1670

> MacNeil C, Dick JTA, Elwood RW (1999) The dynamics of predation on Gammarus spp. (Crustacea: Amphipoda). Biol Rev Camb Philos Soc 74:375-395

Maltby L (1992) The use of the physiological energetics of Gammarus pulex to assess toxicity: a study using artificial streams. Environ Toxicol Chem 11:79-85

Maltby L, Naylor C, Calow P (1990) Effect of stress on a freshwater benthic detritivore: scope for growth in Gammarus pulex. Ecotoxicol Environ Saf 19:285-291

Mandrillon AL, Saglio P (2007) Herbicide exposure affects the chemical recognition of a non native predator in common toad tadpoles (Bufo bufo). Chemoecology 17:31-36

> Massarsky A, Trudeau VL, Moon TW (2011) B-blockers as endocrine disruptors: the potential effects of human $\beta$-blockers on aquatic organisms. J Exp Zool 315A: 251-265

- Maurer M, Escher BI, Richle P, Schaffner C, Alder AC (2007) Elimination of $\beta$-blockers in sewage treatment plants. Water Res 41:1614-1622

Nelson DL, Cox MM (2005) Lehninger priciples of biochemsitry, 4th edn. WH Freeman, New York, NY

> Normant M, Lamprecht I (2006) Does scope for growth change as a result of salinity stress in the amphipod 
Gammarus oceanicus? J Exp Mar Biol Ecol 334:158-163

Orav-Kotta H, Kotta J, Herkül K, Kotta I, Paalme T (2009) Seasonal variability in the grazing potential of the invasive amphipod Gammarus tigrinus and the native amphipod Gammarus salinus in the northern Baltic Sea. Biol Invasions 11:597-608

Oskarsson H, Eriksson Wiklund AK, Lindh K, Kumblad L (in press) Effect studies of human pharmaceuticals on Fucus vesiculosus and Gammarus spp. Mar Env Res doi:10. 1016/j.marenvres.2011.11.001

Owen SF, Giltrow E, Huggett DB, Hutchinson TH, Saye J, Winter MJ, Sumpter JP (2007) Comparative physiology, pharmacology and toxicology of $\beta$-blockers: mammals versus fish. Aquat Toxicol 82:145-162

Palmgrén JJ, Jukka Mönkkönen J, Korjamo T, Hassinen A, Auriola S (2006) Drug adsorption to plastic containers and retention of drugs in cultured cells under in vitro conditions. Eur J Pharm Biopharm 64:369-378

Pascoe D, Kedwards TJ, Maund SJ, Muthi E, Tayloe EJ (1994) Laboratory and field evaluation of a behavioural assaythe Gammarus pulex precopula separation (GaPPS) test. Water Res 28:369-372

Paxéus N (2004) Removal of selected NSAIDs, gemfibrozil, carbamazepine, $\beta$-blockers, trimethoprim and triclosan in conventional wastewater treatment plants in five EU countries and their discharge to the aquatic environment. Water Sci Technol 50:253-260

Råberg S, Kautsky L (2007) A comparative biodiversity study of the associated fauna of perennial fucoids and

Editorial responsibility: Helmut Segner,

Bern, Switzerland filamentous algae. Estuar Coast Shelf Sci 73:249-258

Scott GR, Sloman KA, Rouleau C, Woood CM (2003) Cadmium disrupts behavioural and physiological responses to alarm substance in juvenile rainbow trout (Oncorhynchus mykiss). J Exp Biol 206:1779-1790

Sun H, Mao Y, Wang J, Ma T (2011) Effects of beta-adrenergic antagonist, propranolol on spatial memory behavior in mice. Neurosci Lett 498:133-137

Taylor EJ, Jones DPW, Maund SJ, Pascoe D (1993) A new method for measuring the feeding activity of Gammarus pulex (L). Chemosphere 26:1375-1381

- Ternes TA (1998) Occurrence of drugs in German sewage treatment plants and rivers. Water Res 32:3245-3260

- Wallace WG, Estephan A (2004) Differential susceptibility of horizontal and vertical swimming to cadmium exposure in a gammaridean amphipod (Gammarus lawrencianus). Aquat Toxicol 69:289-297

> Warner RE, Peterson KK, Borgman L (1966) Behavioural pathology in fish: a quantitative study of sublethal pesticide toxication. J Appl Ecol 3:223-247

Wisenden BD, Cline A, Sparkes TC (1999) Survival benefit to antipredator behaviour in the amphipod Gammarus minus (Crustacea: Amphipoda) in response to injuryreleased chemical cues from conspecifics and heterospecifics. Ethology 105:407-414

Zamzow JP, Amsler CD, McClintock JB, Baker BJ (2010) Habitat choice and predator avoidance by Antarctic amphipods: the roles of algal chemistry and morphology. Mar Ecol Prog Ser 400:155-163

Submitted: April 13, 2011; Accepted: September 23, 2011 Proofs received from author(s): November 12, 2011 